\title{
STUDIES IN RELATION TO MALARIA.
}

\author{
II. \\ THE STRUCTURE AND BIOLOGY OF ANOPHELES \\ (Anopheles maculipennis). \\ THE EGG AND LARVA.
}

\begin{abstract}
By George H. F. NUTtall, M.A., M.D., Pir.D., University Lecturer in Bacteriology and Preventive Medicine, Cambridge;

AND ARTHUR E. SHIPLEY, M.A., Fellow and Tutor of Christ's College, University Lecturer on the Advanced Morphology of the Invertebrates, Cambridge.
\end{abstract}

(From the Pathological and Morphological Laboratories of the University of Cambridge.)

THE importance of malaria as a disease affecting vast numbers of the human race renders it essential that we should study most completely all that affects the etiology of the disease. Through the brilliant researches of Ross, Grassi, Bignami and Bastianelli, and others we know that several species of Anopheles serve as definitive hosts of human malarial parasites, and that when these insects are infected they are capable of communicating the parasite to man. As far as the evidence goes these insects appear to be the only means by which the disease is spread. The sexually mature parasites circulating in man's blood gain access to the insect when it feeds upon this fluid. After a period of 7 to 8 days, under suitable conditions of temperature, the parasites appear in the insect's saliva, and when this occurs the latter is capable of producing infection by the act of biting. The highly interesting literature on this subject has been considered elsewhere by one of us, as also by Lühe, and the reader is referred to these publications for particulars ${ }^{1}$.

1 See Bibliography at the end of the Paper. 
Other parasites besides those of malaria have recently been found to undergo their development in species of Anopheles. In 1878 Manson first observed the development of Filaria bancrofti in a species of Culex, and this observation has been confirmed by others. Quite recently Low (July 1900) observed that the matured Filariae issued from the proboscis of Culex ciliaris; and James (1 Sept. 1900), working at Travancore in India, has proved that this parasite developes in Anopheles rossii and another undetermined species of this genus, as also in Culex microannulatus and Culex albopunctatus Skuse. Finally Grassi and Noè (Nov. 1900) claim to have observed a similar development of a canine parasite, the Filaria immitis, in Anopheles maculipenris. The latter authors state that the geographical distribution of Filariasis in the dog corresponds with the geographical distribution of malaria, as also of Anopheles in Italy. Their observations made by injecting filariae which had matured in these insects though insufficient in number, certainly indicate that Low's hypothesis with regard to the mode of infection is probably true. The literature on Filariasis up to the time immediately preceding Low's discovery will be found in a paper (1900) by Nuttall to which the reader is referred. ${ }^{1}$

It seems desirable to briefly summarize the recent advances not mentioned in the publications of Nuttall already referred to. Ziemann (21 June, 1900) working in Cameroon found two undescribed species of Anopheles in dwellings occupied by whites and natives ${ }^{2}$. Of the insects examined $30 \%$ harboured parasites resembling those of malaria in their stomach wall. He reports that he was able to infect these insects with crescentic and tertian parasites, whereas these parasites did not develope in a species of Culex nor in Sandflies, the latter being very numerous. Van der Scheer and van Berlekom (1900), who have studied an outbreak of malaria at Middleburg in Zeeland (Holland), found that most of the cases occurred in the outskirts of the town, especially to the west. They noted house-epidemics, persons in the immediate neighbourhood remaining unaffected. The type of fever was single or double tertian. There were 110 cases in 45 houses. They found A. maculipennis in houses, stables, and huts, the insects feeding on human and animal blood. In July and August these insects were not infrequently found in human habitations. One-fifth of the Anopheles examined were found to harbour malarial

1 See Bibliography at the end of the Paper.

2 It is most desirable that investigators should state with what species of Anopheles, etc. they have experimented. 
parasites in the stomach wall. They caught Anopheles and fed them on tertian blood, after which they observed the development of the parasites inside the insects. Of 5 insects kept at 18 to $21,5^{\circ} \mathrm{C}$, 4 became infected. Another observation showed that 18 out of 22 insects similarly fed became infected. When the insects were fed with blood containing immature parasites, with the blood of persons who were being treated with quinine, or with the blood of persons who had recovered from malaria the result was negative. Their observations show that Anopheles may become infected at a lower temperature than Grassi has claimed to be necessary in Italy. The publication is illustrated by means of micro-photographs showing the development of the parasites, as also by a photograph giving a very characteristic picture of $A$. maculipennis.

Manson (Sept. 1900) obtained Anopheles (spec. ?) from Rome through Bignami and Bastianelli, these investigators having infected them with benign tertian parasites. The insects arrived in London after a journey of about 48 hours. Dr Manson's son, Mr Thurburn Manson, allowed himself to be bitten by the infected insects. Owing to his having been bitten by three lots of insects the period of incubation was not clearly established. The result of the experiment was however perfectly conclusive for Mr Manson subsequently developed tertian malaria. It has further been reported by Rees (Oct. 1900) that $\mathrm{Mr}$ George Warren was similarly infected by Anopheles (spec.?) imported from Rome. He acquired tertian malaria (benign) after an incubation period of 14 days. The experiments reported by Manson and Rees and made upon healthy individuals in a country free from malaria should fully convince those who may have remained sceptical.

Of $42^{1}$ well-identified species of Anopheles eight or more have been proved to serve as hosts of the malarial parasite ${ }^{2}$. Experiments with these species have been made in India, Italy, Africa, the United States, Holland, and England. There are three species known in England: Anopheles maculipennis, Anopheles bifurcatus, and Anopheles nigripes ${ }^{3}$.

1 We are indebted for information with regard to the number of known species to Mr F. V. Theobald, who is publishing a monograph on the genus Anopheles from material supplied to the British Museum from all parts of the world.

2 A. maculipennis, bifurcatus, pictus, pseudopictus, nigripes (?), rossii, funestus, and a fow as yet undetermined species.

3 A. bifurcatus and A. nigripes are regarded as varieties of one species by Ficalbi (1899) and Grassi (1900). We have the authority of two eminent British dipterists (Messrs F. V. Theobald, F.E.S. and G. H. Verrall, F.E.S.) for the statement that they are perfectly distinct species. We are indebted to $\mathrm{Mr}$ Theobald for his determination of the 
Of the three, the first, as will be seen from perusal of the preceding paper $^{1}$, is by far the most common, as it is also the most common and wide-spread species upon the European continent. It was whilst experimenting with this species that Grassi, Bignami and Bastianelli made the first studies upon the complete life cycle of the human parasites. For this reason it seems eminently desirable to give a careful and detailed description of this species, accepting it as a type of the genus all the species of which probably play a similar part in the propagation of malaria. We hope in a subsequent paper to supplement what may be lacking in the present publication. Though parts of this study may appear somewhat technical, the importance of the subject seems to us to warrant all the detail. There is scarcely a greater problem presented to modern hygiene than the extermination of malaria which renders vast portions of the globe almost uninhabitable to the white man. For this reason we should hasten to know all that concerns the insects which convey it.

\section{Historical Note.}

The first reference to Anopheles which we have found in the literature is that of Joblot (1754) of Paris, who describes the larva as rare, under the heading: "Description d'un nouveau poisson" or "Chenille aquatique." $\mathrm{He}$ gives a fairly good figure of the larva considering the instruments he must have used. Fischer (18121813) figures "Culex claviger," the larvae being those of Corethra. Meinert mentions that Gercke refers briefly to the larva in his Zur Metam. d. Dipt. Gatt. Dixa. Brauer (1883) mistook the larva of Anopheles for that of Dixa, his figure being poor, whilst his enlarged figure of the head shows that he mistook the ventral for the dorsal aspect. Meinert (1886) gives fairly good figures of the larvae of $A$. maculipennis and $A$. nigripes, the figures showing the whole larva, as also various parts studied in detail. Descriptions have been published more recently by Ficalbi (1899) and Giles (1900). The various stages in the evolution of $A$. maculipennis (Syn. A. claviger, A. quadrimaculatus) have been described and figured by Grassi and by Howard

following synonymy of the three British species above named: A. maculipennis Hoff. $=A$. bifurcatus Meig. 1804, A. claviger Fabr. 1805, A. quadrimaculatus Say: A. bifurcatus Lin. $1758=$ A. claviger Meig. 1804, A. trifurcatus Fabr. 1792, A. villosus Robineau Desvoidy 1827, A. grisescens Stephens 1828: A. nigripes Staeger 1839=A. plumbeus Haliday. We have added some dates from Ficalbi's monograph.

1 Studies in Relation to Malaria, Part I. p. 12. 
(1900). It cannot be said that any of the descriptions hitherto published give a full and satisfactory account or entirely accurate figures showing the development of Anopheles. As to the representations which have appeared in medical literature they have been either incomplete or very inaccurate.

\section{The Ovum.}

When first deposited the eggs are white, but they soon darken. Each ovum measures 0.7 to $1.0 \mathrm{~mm}$. in length and is at its greatest breadth about 0.16 broad. The egg is boat-shaped and one end is slightly deeper and fuller than the other. The surface which, were the egg a boat, would be the upper is flattened but slightly convex. It is marked by minute reticulations (Fig. 2). The under surface of the boat is characterized by much larger and more regular reticulations, which divide the surface into fairly equal hexagonal areas. The rim $(a)$ of the boat is thickened and very regularly ribbed. Along the centre of each side, extending over a space of rather more than one-third the total length, this rim is much thickened, the ribbing is more marked and the whole forms a very conspicuous and characteristic feature of the egg. This thickening recalls the rounded float which runs along the edge of a life-boat (Fig. 1). It serves the same purpose, being composed of air chambers and is used to keep the boat-shaped egg with its flat surface uppermost. Howard (1900, p. 35) refers to the membrane we are about to describe as the "clasping membrane," notes the reticulated surface exhibited by the eggs, as also the presence of $5-7$ minute dark circular spots at the ends. His measurement of the egg is given as only $0.57 \mathrm{~mm}$. As in other insects the egg doubtless varies in size.

The colour of the egg soon after it is laid is grayish black. If the eggs are subject to much attrition a delicate membrane splits off which gives the surface of the intact egg its reticulated appearance. Stripped of this membrane, which desquamates in irregular whitish fragments, the egg appears with a glistening black surface comparable to that of patent leather. One end of the egg is slightly blunter and more rounded than the other, and this contains the head end of the embryo. It is an interesting point that when the egg, as frequently happens, is drawn by capillary action a little way up from the water on to a leaf or some other half-submerged object the head or blunt end always points downwards, and thus should the hatching take place whilst the egg is in this position the larva emerges into the water, and not into the air. 
We have observed that the eggs floating upon the water slightly indent the surface-film.

According to Grassi (1900, p. 66) the female deposits about a hundred eggs upon the water. Howard (p. 35) says the eggs number 40-100. According to Grassi the eggs of A. maculipennis lie in groups of $3-20$, side by side like a bridge of boats, whilst those of $A$. bifurcatus arrange themselves in star-like patterns, their ends being in juxtaposition. He only found the eggs of A. superpictus once, the eggs being scattered. The eggs of Anopheles do not adhere to each other as do those of Culex, the result being that they are readily scattered by the wind. It has however been observed in our aquaria that if left undisturbed upon the surface they tend to collect together, as do other small bodies even of an inanimate nature which float upon water.

Our observations do not in all respects confirm those of Grassi as to A. maculipennis. In the still aquaria of a laboratory the eggs certainly lie as he describes, but in the open pools in Great Britain, that is to say in their natural state, they seem to be invariably scattered. Empty eggshells are often met with, and they too in natural water about Cambridge are always scattered.

The eggs are laid upon water suitable for the development of the larvae, that is usually water rich in vegetable matter such as Algae. Grassi states that he first found eggs on the 15th of February, 1899. In the spring $A$. maculipennis and $A$. pseudopictus lay their eggs in water about 2 feet deep, later when the weather grows warmer the eggs are laid in water but a few centimeters deep. On the other hand Grassi (4 Oct., 1899) says that $A$. bifurcatus lays eggs in cool weather by preference in shallow water, especially such as contains cress. Grassi only found larvae in the end of March on the Pontine Marshes, their number increasing as summer advanced, whilst they were still encountered in September and October. In November his servant only found one larva of $A$. maculipennis after two days' search in the Campagna.

On the second or third day after oviposition, this depending upon the temperature ${ }^{1}$, the young larva leaves the egg and commences to swim in the water. The egg hatches by means of a circular split near the blunt end of the egg-capsule. This separates a cap-like anterior

1 Howard reports that eggs laid on the 26th of April hatched out on the 30th. Some others laid on the 13-14th of May hatched out on the 16-17th. On an average the eggs hatched out three days after being laid. He does not note the temperature, which is certainly important. 
piece from the rest of the shell. There is no visible ring where the cap breaks off, but the cap is usually more or less of the same size.

Ross (23 July, 1900) ${ }^{1}$ made an observation which indicated that the eggs possessed a considerable degree of resistance to desiccation. Some eggs of Anopheles kept in a test-tube hatched on being placed in water after a period of about six months. In a recent publication he throws doubt upon the accuracy of this observation, stating that it requires confirmation. It certainly finds no support from what has been seen by recent observers. Some eggs which we placed on filter-paper and under glass for less than five days did not give rise to larvae when floated upon the water of an aquarium. Christophers and Stephens (Aug. 1900, p. 8) found no eggs in dried pools at Freetown although they were present as long as there were moist cracks in the hollow which had contained water. The same authors state elsewhere (6 July, 1900, p. 48) that they found Anopheles eggs would hatch after being dried for 24-48 hours on blotting-paper, but that no larvae issued when more than 48 hours had elapsed. Tests made with earth taken from 25 pools gave a negative result. Gray (1900) of St Lucia, W.I., took mud from a pool that had been dried three weeks and added water to it, but the result was negative. Some grass taken from the pool margin and placed in water gave a positive result, in that larvae of Culex taeniatus appeared within 24 hours. From these observations we see that the matter requires to be further investigated. It is quite possible that the resistance of the eggs may vary according to the season at which they are laid, and that the eggs of Culex are more resistant than those of Anopheles. We have no evidence to the effect that eggs can withstand hibernation, everything indicating that they are carried through the winter solely within the female's body, and only attain maturity in early spring when the weather grows warmer.

\section{The LaRva.}

The body of the larva is divided into three regions:-(1) the Head, (2) the Thorax, (3) the Abdomen. The segments of the thorax are much fused together, still traces of a division into three are not wanting. The abdomen may be divided into nine segments. The first seven of these exhibit but a slight and gradual change of form, the eighth is rendered conspicuous by carrying on its dorsal surface

1 Personal communication. 
the stigmatic apparatus, and the ninth or last is equally conspicuous (Figs. 3 and 4).

\section{The Head of the Larva.}

The head of the larva is much more rounded than is usually represented, in fact the diameter from above downwards is very little less than from side to side, except anteriorly, where the dorsal surface slopes downwards and forwards (Fig. 7). The head is covered with a very complete and clearly defined chitinous case. The posterior edge of this is sharply cut and almost circular in outline. It is very little smaller than the biggest cross section of the head, and is strengthened by a slightly thickened band which runs like a clerical collar round the posterior, free edge. The chitinous cover is brown, lighter where there are joints, e.g., at the insertion of the antennae; and darker where the chitin is thickened, e.g., at the bases of some of the appendages. In Chironomus the ventral border of the chitinous covering of the head is cut away in the form of a bay, thus allowing the head to be flexed on to the thorax, but in Anopheles the edge of the chitin of the head is even and in no place curved in. In the dorsal middle line however the thickened band is cut in two and there is a narrow gap or slit between the two cut edges (Fig. 8). From the anterior end of this slit two lines of pigment diverge, forming the posterior sides of a diamond-shaped area on the upper surface of the head; there is in some larvae also a median ventral slit.

The eyes are situated quite laterally, and they seem to be of two kinds, one is compact and more or less circular in outline, the other, which is only visible in the older larvae, is a cycle-shaped body compounded of isolated ommatidia. These lie above and a little in front of the rounded eye, and it would seem that they are beneath the transparent cuticle and are in fact the primordia of the adult eye. The level of the eyes is at about the juncture of the posterior third with the anterior two-thirds of the head. Between them on the arched upper surface the head bears a line of four symmetrically arranged branching ${ }^{1}$ hairs, which are difficult to see (Fig. 4).

In front of the eye at about the same horizontal level is an eminence which carries the antennae, and this eminence is partly caused by a slight but deepening groove which runs in front of the eye and helps to mark

1 We have used the term branched when the branches of the hair in question lie in more than one plane, feathered when they lie in one plane. 
off a central area of the upper surface of the head from a lateral portion which is continuous with the sides. Between the two eminences a broadish band of pigment runs across the head on the dorsal surface, and this bears six symmetrically placed feathered hairs which project forward over the head (Figs. 4 and 7). These remarkable and characteristic hairs never seem to move, the tips of the central hairs reach forward in front to the anterior end of the head, over which they hang like a kind of "glory." It may be that they serve as a buffer to shield the head, but judging from the usual movements of the larva, which generally take place tail foremost, danger from this cause is little to be apprehended.

Anteriorly the head which has narrowed,-since the groove above mentioned has deepened and passed on to the side,-is cut off by a sharp edge and the most anterior end of the animal is formed by an area supported above and on both sides by the chitinous edges of the head but ruuning into soft tissue on the ventral side in front of the mouth. This membrane is almost vertical, but slopes slightly backwards and downwards. At each corner of the dorsal chitinous end of the head is placed a conspicuous branched hair (Fig. 4), which exactly overhangs the brushes shortly to be described. In the middle line or rather close to it, two simple pointed hairs (Fig. 4) slightly frayed at their free ends project forward. These are very fine, and lying as they do with their ends near together often look like a single stout hair, closer examination usually shows that the tips are crossed and that there are really two hairs ${ }^{1}$ Grassi (1900, Plate Iv.) has drawn attention to the fact that these branched hairs at the corner and the two simple or slightly frayed hairs near the middle are of specific importance and has given figures showing the differences which exist in A. claviger, $A$. pseudopictus, A. superpictus and $A$. bifurcatus. There are other smaller hairs on the head but those mentioned are the most conspicuous.

The anterior end of the head carries on each side of it a very conspicuous bunch of stout, dark brown hairs (Figs. 7 and 8) which have some sort of a spiral arrangement and are slightly curled. The hairs are as closely aggregated as those of a shaving-brush. Between the bases of the two brushes is a smaller bunch of hairs, and ventrally there are two semicircles of hair, all above, in front of and converging on the mouth.

The anterior median area which carries the brushes is called by Meinert the 'clypeus.' In older larvae it is produced into a conical spine or process, very difficult to see, which underlies the two median

1 For the sake of clearness these branched and frayed hairs have been omitted from the enlarged views of the head (Figs. 7 and 8). 
hairs. This gives a kind of finish to the head but it does not seem to be present in the younger larvae. There is also a pair of chitinous bars in this area which will be considered more in detail when an account of the head muscles is given.

The muscles which move the bunches of hairs are two pairs, symmetrically placed. The internal pair have their origin from the dorsum of the head, the point being indicated by a symmetrical patch of pigment situated in the posterior angle of the diamond-shaped area on the head about the level of the eyes. The muscles arise almost in contact and run almost parallel, but very slightly converging to the middle anterior end of the head where they are inserted on the soft membrane, but between the bases of the brushes.

The external pair of muscles have their points of origin separated by a space about equal to half the diameter of the head. Their origin is also marked externally by a patch of pigment which lies just within the lateral angles of the aforenamed diamond-shaped area. These muscles are stout and converge towards the anterior end of the head where they are inserted into the area which bears the brushes, but external to the median or internal muscles. Their direction is inwards, forwards, and slightly downwards. Their point of origin is within and in front of the eyes.

A third pair of stout muscles have their point of origin near the posterior edge of the head-case and are more laterally placed. In fact they are external and posterior to the eye-complex whereas the relations of the point of pigment of the external brush muscles to the same organ are internal and anterior. These muscles run more obliquely downwards than do either of the above-mentioned pair. We have not been able to follow them to their insertion, but we have no doubt they are inserted into the maxillae and that their contraction causes the very vigorous movement of the organs whilst the animal is feeding.

In a future Paper we hope to give a full account of the muscles of the head, here we must content ourselves with the bare mention of the three largest.

\section{The Appendages of the Head.}

The only appendages borne by the larva of Anopheles are those of the head, though possibly the larger hairs of the thorax may correspond in position with the future legs.

The head appendages are paired and consist of (i) Antennae, (ii) Mandibles, and (iii) 1st Maxillae. 
The antennae may be described as two jointed, though the first joint which is quite short seems immoveably fixed to the chitinous covering of the head. The second joint is elongated, moveable, and provided with a few spines. Its free end is truncated, and bears two large spines slightly curved. These can be separated one from another and brought together again. Between the bases of these spines a very minute spine has its origin and also a branched hair which is rather longer than the large spines (Figs. 7 and 8).

The mandibles consist of one joint forming the side of the mouth, which is floored by the maxillae (Figs. 7, 8 and 11). Each mandible is a stout piece, articulating by a broad base with the under, lateral part of the head. Its free, anterior border bears passing from without in wards the following structures. Most externally three, sometimes four (?) strong cycle-shaped hairs which in a position of rest often touch the posterior, outer angle of the brushes of hairs, and so help to form a kind of sieve to entangle any particles of food which may be approaching the mouth. These hairs are sometimes run through the brushes and serve to clean and arrange them. More internally the mandible is produced into a number five or six, stout, chewing teeth which judging from their colour must be strongly chitinized. These teeth working against those of the opposite mandible are the only crushing apparatus the larva possesses. More internally still is a bunch of hairs which line the mouth (l. Fig. 11).

The larva of Anopheles has a single pair of maxillae, the first. There is nothing which can be homologized with the second pair. Each maxilla is a somewhat flattened, quadrilateral strongly chitinized piece, the inner edge of which approximates to its fellow of the other side but does not touch it. In the angle between them lies a conical, toothed piece-the "under lip" of Meinert (q. Fig. 8). The maxillae take by far the largest share in flooring-in the space in which the foodparticles accumulate. The upper surface of each is covered with fine hairs like a carding brush, these are arranged in two areas separated from one another by a space devoid of hairs, which runs from the anterior, inner corner obliquely backward. The hairs of the inner area point outwards and forwards, those of the outer inwards and forwards (Fig. 12). At the anterior edge some of these hairs project and are curved, and these are especially well marked towards the outer side. From this description and from Figure 12 it will be seen that the inner surface and the anterior edge of the maxilla act as a most efficient brushing or combing instrument which cards through the hairs of the brushes and 
clears them of any particles entangled in them and combs them out. The maxilla is united to the head by a wide, spacious joint.

The maxilla bears on its outer edge a palp which lies in a plane slightly dorsal to the maxilla and helps to form the sides of the abovementioned space in which the particles of food are collected together. The palp consists of a single joint which bears at its end three spines. Between the spines in a manner indicated in Figure 12 a thin lamella of very definite shape but of a soft membranous nature projects. The single joint bears many minute hairs and a cluster of longer ones towards the end, close to the spines.

\section{Method of Feeding of the Larva.}

On the extreme anterior end of the head are the two closely packed bundles of slightly curved fine, hair-like setae, which we have throughout this Paper called the brushes. Other observers have called them the rotatory, whirling and vortex organs, a name which suggests that the individual hairs move in succession and create a whiripool. This is however not the case. All the hairs move together and both organs move as a rule simultaneously and in the following way. The hairs are arranged in a sort of cupped, fan-like shape, something like a very strong, overhanging, arched moustache. Their point of origin is attached to the extreme anterior edge of the head, and this portion of the head, the "clypeus" of Meinert, is hinged on to the rest of the head; the whole organs can be bent on this hinge, and when bent the two bunches of hair also tend to come together towards the middle line. The two brushes however can move independently, and at times one is seen bent under whilst the other remains erect.

Whilst feeding at the surface, which seems to be the chief occupation of the larva, the head is reversed so that the ventral surface lies uppermost, the body retaining its normal position. This peculiar rotation of the head does not take place in the larva when it feeds at the bottom. Almost immediately upon returning to the surface it suddenly turns its head on its neck as an axis, through an angle of $180^{\circ}$. This is done suddenly and with such precision that one almost expects to hear a click. The mouth-parts now begin to vibrate backward and forward and the brushes are bent rapidly downwards, backwards, and inwards. When at rest, the outer end of the curved moustache is almost touched by the free end of the maxillary palp (Fig. 8). This organ helps thus to form the sides of a space at the bottom or posterior 
end of which the mouth lies. The walls of this chamber are completed by the mandibles, the curved hairs of which, whose function is considered above, are frequently projected so as to just cover the tips of the outermost hairs of each brush. The floor of the above-mentioned space is mainly formed by the two flattened maxillae, which curve under like the ribs of a boat and almost meet in the middle line. Their inner borders are separated by the conical process with two or three teeth on each side, the so-called "under lip" of Meinert. Together with the maxillae it floors the space into which the brushes are bent back, and which is roofed by the under surface of the head.

When the larva is feeding the brushes are suddenly bent back into this space, the mandibles and maxillae moving forwards to meet them and at the same time opening out, they are then as suddenly released and fly back to their original position. This movement of sudden bending and swift relaxation is repeated with great rapidity, often some 180 times a minute, producing a current sweeping in convergent curves towards the above-mentioned cavity. The water filters out on each side, but any particle of food is retained by the complex of fine hairs which are borne by the mouth appendages.

From time to time the mandibles are approximated and the stiff curved hairs of their upper edge are run through the brushes like fingers through the beard, and thus the mandibular curved hairs help to arrange the hairs of the brushes and keep them in their order. They may also assist in removing any particles of food that may be entangled in the brush. That this is of importance is shown by the fact that at intervals, generally at the end of a certain number of contractions, the brushes disappear far into the mouth and are then slowly withdrawn, passing through the fine carding bristles on the inner face and anterior edge of the maxillae. In this way any particle of food which may have become entangled on the brushes is carefully separated and remains on the mouth side of the maxillae. The brushes are frequently swallowed again and again and withdrawn in little jerks, so that the fine teeth-like hairs which act as a carding instrument have every opportunity to comb out any particles entangled in them. It is a most fascinating operation to watch.

From the position of the larva when feeding, the head with its brushes lies close below the surface-film, the currents set in motion by the action of the brushes extend to a distance equal to twice or thrice the length of the larva or even further. The currents seem to be in a plane just below the surface-film and to affect the organisms and 
organic debris, which being lighter than water, float up from the bottom of the pond or puddle and lie under the surface-film. In fact the larva sweeps the lower surface of the surface-film of the water, just as a ceiling might be brushed to remove the flies and spiders which may have settled there.

\section{Food of Larva.}

The food of the larva seems to consist in the main of spores of freshwater algae, particles of Spirogyra, diatoms, and any other minute organisms which do not penetrate the surface-film. The larva may be seen to browse about the decaying leaves of Lemna. They do not feed for any length of time beneath the surface, and when they do so the head is held in the normal position and moved about somewhat like that of a caterpillar, the insect browsing about over the surfaces of sunk particles overgrown with algae, etc. We can confirm the observation of Grassi $(1900$, p. 58) that larvae are best reared when there are few in the aquaria. We have always taken the precaution however to remove any other animals that were inimical. We have on several occasions observed larvae devouring their dead fellows. Gray (1900, p. 583) of St Lucia, W. I., also finds that Anopheles' larvae there are not altogether vegetable feeders, as some would appear to believe, and has likewise seen them feed "on the dead bodies of drowned mosquitoes." Grassi (1900, p. 58) thinks that a small amount of Lemna in aquaria favours the growth of larvae, though they develope best in the presence of confervoid algae. He found the intestine to contain protozoa, unicellular algæ and organic detritus. Howard $(1900$, p. 39) observed that the dark central axis of the larvae (A. maculipennis) was due to the nature of the food contained in the intestine, and that when the larvae were fed on algae their bodies turned green. Finally Christophers and Stephens (Aug. 1900, p. 3) found Anopheles' larvae in Africa feeding chiefly on a unicellular organism (Protococcus?).

At times some structure larger than the larva can swallow is involved in the current set up by the brushes. A short, sharp struggle ensues and after an effort or two the morsel is rejected. The particles that are swallowed accumulate for a certain time, until a mouthful of some size is attained and this then suddenly passes into the oesophagus.

As is well known the larva of the gnat, Culex, hangs down into the water attached to the surface-film only by its respiratory siphon. It 
sweeps the water for food some two or three millimeters below the surface. It is devoid of the palmate hairs which enable the Anopheles larva to float with the whole length of its body close to the surfacefilm. The habit of feeding upon matter adhering to the surface-film has only been observed by us in the larvae of two insect genera; Anopheles and Dixa. ${ }^{1}$. The fact that certain fresh-water Snails and many Turbellaria browse over the same area is further evidence that as a feeding ground it is by no means unworthy of notice.

\section{The Thorax.}

In youngest larvae the head is decidedly broader and deeper than the following segments, in older larvae (Fig. 3) the segments which follow the head have surpassed it in the area of their cross sections, whilst in the fully grown larvae (Fig. 4) about to pupate the segments which succeed the head are at least twice its diameter.

1 The larva of Dixa, which possesses a resemblance to Anopheles, and has often been mistaken for it, also floats beneath the surface-film. We have caught about 14 Dixa larvae this summer in the same places where Anopheles were captured. Dixa larvae may be distinguished at a glance from those of Anopheles by the fact that the " respiratory-cup," as Miall $(1895$, p. 157) styles it, is much larger and that only this organ and the vibratile mouth-parts touch the surface. The larva has no palmate hairs such as enable Anopheles to float flat, and the body of the Dixa larva is usually submerged with its dorsal surface concavely arched. The area of the respiratory-cup of Dixa is considerably increased by numerous simple marginal setae arranged like pine-needles on a stem, and it is owing to the greater size of this organ that it alone suffices to maintain the larva near the surface. Whilst the thorax is large in Anopheles, all the segments in Dixa are of fairly uniform size. Whereas Anopheles swims tail first and downward when disturbed, Dixa swims head first, and usually maintains itself upon the surface. In swimming only the anterior four segments lash laterally, the remainder of the body remaining rigid. Examined microscopically Dixa is seen to possess four prolegs ending in hooklets as in caterpillars, these prolegs issue anteriorly and from the ventral surfaces of the 4 th and 5 th segments. Whilst Anopheles in feeding on the surface rotates its head so that it turns bottom side up, Dixa bends its head backward upon its neck so that it forms a right angle or less with the body. The result is that whilst Anopheles attracts particles from in front towards the head, Dixa attracts them from behind. By using its prolegs Dixa creeps up the side of a vessel or stem, the anterior and posterior portions of the body remaining pendulous. Already Réaumur (1714, Mém. de ''Acad. Roy. de Paris) compared this position to that of a siphon and observed the larva advance or retreat with the water at the edge of the vessel when the latter was tilted to and fro. Figures of this larva will be found in Meinert (1886) and Miall (1895). As the latter points out the Dixa larva does not break the surface-film in creeping up the side of a vessel for it drags up a part of the film with it. He has however observed these larvae occasionally wander out of a vessel and perish from drying up. When the larva sinks a bubble of air is often carried down in the respiratory-cup, and the larva when below swims somewhat like a worm. From this short description it will be seen that there should be no difficulty in distinguishing the larvae of Dixa and Anopheles even with the naked eye. 
Throughout the Diptera in the imago "the thorax is remarkable from the absence of distinct separation into the three divisions which may usually be so easily distinguished in Insects ${ }^{1}$," and this peculiarity is exhibited in the larval Anopheles, as far at any rate as the external features go.

The thoracic region in the older larvae is broader than the head and broader than the succeeding segments, which taper very slightly to the tail.

On each side of the middle dorsal line of the anterior rim of the thorax is a line of three feathered hairs, increasing in their size from within outwards and spread forward overhanging the head. Overhanging the base of these is a curious, flattened, notched process, only to be seen when under a very powerful light (Figs. 4 and 6 ). On the ventro-lateral border on the same edge emerge on each side a pair of large feathered hairs, sometimes double from the base, these resemble the dorsal hairs and also those which are now to be described.

A very little way behind this row of hairs come on each side of the prothorax two hairs usually feathered; these are distinctly lateral in position and are almost always directed forward, even when the first and third rows are standing out at right angles to the body. This second row of four hairs is not so conspicuous as the others and do not seem to conform to the same series, but for this they might be looked upon as the bristles of the mesothorax.

At a greater distance than separates row one from row two comes row three, which is in fact near the posterior edge of the thorax. This consists of a row of four feathered hairs projecting as a rule forward, though often outward. Each row of four hairs is lateral, and not unfrequently one of the four is broken off. There are numerous small, usually simple hairs, for the most part symmetrically arranged on the thorax besides these specially mentioned.

\section{The Abdomen.}

The first two segments of the abdomen, which consists of nine segments, each bear at their lateral, posterior angle a pair of similar bristles. Where they arise the surface of the segment is projected almost like a parapodium. The third segment, at any rate in younger larvae, carries but one of these feathered hairs. Each is feathered, i.e. branched in one plane only, and this plane is at right angles to the

1 D. Sharp. Cambridge Natural History, Vol. vi. p. 445. 
long axis of the body. They protrude out from the body, arching slightly forward, for a distance on each side equal to at least double the width of the body in the younger larvae. They undoubtedly act as balancers, like the sculls of a rowing skiff, but they do not seem to exercise independent movement.

Near to the base of these large lateral hairs, and on a line which slopes inwards and slightly forwards, are on each side of the dorsal surface four small hairs. The most external of these is a branched hair with a very short stalk, and the branches of which are simple, fine, rounded hairs projecting in a bunch. The second hair passing inwards is a single, straight, unbranched hair of some length, about as long as the body is broad, the third and fourth hairs are branched like the first but are much smaller, and the fourth is smaller than the third (Fig. 13).

Nearer to the middle line than the innermost of the four hairs just described, but not in the same line, being a little posterior, but distinctly on the upper surface of the animal is a small conically branched hair. On the 1st and 2nd segment behind the thorax this hair is small and inconspicuous, but on the 3rd, 4th, 5th, 6 th, and 7 th segments they are highly modified and play a very important part in the life of the larva. We call these five pairs of specialized hairs palmate hairs. The significance of these hairs seems to have been hitherto entirely overlooked.

Each of the hairs has a little but very distinct stalk, like the handle of the framework of an umbrella (Fig. 5). At its free end this stalk bears a conical bundle of fine hairs placed like the ribs of the umbrella if one imagines it turned slightly inside out, about onethird of the ribs missing and the remainder somewhat flattened and spindle-shaped in outline. The whole forms a most delicate little cup, and it is by means of these five pairs of palmate hairs which cling on to the surface-film that the larva maintains its position close under the surface of the water. This cone is not quite complete, a few of the inner hairs wanting, in fact the circle wants a segment of about $80 \%$ on its inner edge. The palmate hairs may at times be seen to enclose air-bubbles when the larva is submerged.

The large lateral feathered hairs which form a series along the side of the thorax, and the first two post-thoracic segments, become as is mentioned above single on the third post-thoracic segment and on the fourth is represented by a single hair which has two branches only, and on the fifth by a single unbranched hair, on the sixth and seventh the corresponding hair is small and insignificant whilst the branched hairs 
internal to it on the dorsal surface become larger and more conspicuous as we pass backward (Fig. 4).

The hairs on the ventral surface are either simple, unbranched, or they have a short stalk which ends in two or three, sometimes more, straight simple hairs diverging at equal angles. One of the later lies about on a level with the large hair or its representative, another lies a little internal and anterior to this. A third hair, and this time a simple one, lies still more internal, the bases of these three making a roughly speaking equilateral triangle. In front of the third single hair and in a line with it lie two very small hairs (Fig. 14).

This is roughly speaking the arrangement on the fourth abdominal segment, on the fifth one of the hairs which appears to correspond with the forked hairs above the chief hair becomes feathered and lies backward, and on the sixth and seventh two, one above and one below, become similarly feathered and lie back, overlapping the following segments just as the feathered hairs on the thorax and first and second abdominal segments lie forward, though in size the two are not at all comparable. The exact arrangement and position of these hairs appears to differ after each moult.

The eighth abdominal segment is modified in connection with the opening of the respiratory apparatus, but this chiefly affects the dorsal surface, the hairs on the side and under surface do not suffer much change although the large feathered hairs projecting backward are absent or modified. The hairs which seem in relation with the stigmatic apparatus are described with that organ.

The ninth segment at the posterior end of which opens the anus is modified in shape, being no longer rather flattened and squarish in cross section but round, and the whole segment is cylindrical. It bears some very remarkable hairs, but with the exception of these which will shortly be described and two single hairs which proceed from the side about half way along the cylinder, the hairs which are so characteristic of the other segments are wanting. The surface of this last segment is beset with very minute pointed bristles, all pointed backwards and giving the portion of the skin so characterized a shagreen-like appearance (shown in Fig. 3).

The posterior end of the body is cut off sharp and presents an oblique, plane, round surface (Fig. 9). Near the centre of the round disc the anus opens, a little ventral to the exact centre. Surrounding it, and placed dorso-laterally and ventro-laterally on each side, quite symmetrically are four soft, white, anal papillae, which when fully extended may 
attain a length almost two-thirds as long as the ninth abdominal segment. The anal papillae are well supplied with tracheae and are clear, transparent structures with considerable powers of retraction. The posterior end of the rectum is liable to a prolapsus and often extends some distance out of the anus, this is, we fancy, the result of pressure and does not occur in nature except at the moment of evacuation.

On the dorsal side of the posterior rim of the ninth abdominal segment are four very prominent and remarkable hairs : two median and two lateral (Fig. 9). They hang back over the anus in a very characteristic and graceful manner. The two right and the two left hairs arise in close proximity, but the median right and the median left, which also arise close to one another and to the median line, immediately after their origin come to lie in contact, and thus it requires careful observation to see that there are in reality two hairs and not one. The hair is of the feathered variety, the branches being in the horizontal vertical plane, and the first four or five are on the dorsal side only. Nearer the tip, however, we find branches on each side of the central axis. The two feathers hang back over the anus in the median vertical plane, but are arched up dorsalwards. The lateral right and left hairs are not so much feathered as the central, indeed they are strictly speaking not feathered at all but forked, the four or five branches into which they split all arising at about the same level. These two hairs project backwards and slightly upwards and outwards, and are symmetrically arranged. The four form a very beautiful structure.

Ventrally the ninth abdominal segment bears a wonderful fan-shaped arrangement of hairs springing from two skeletal pieces of singular structure. The basal apparatus is paired, and each half resembles a quarter of a solid oval. The convex surface is externally, one of the straight sides looks upwards and the other faces the corresponding surface of its fellow. Inserted along the convex surface of each is a uniform row of nine feathered hairs, which have their origin in a very distinct circular articulation. The hairs of one side are closely applied to the hairs of the other, pair after pair, so that seen sideways the apparatus looks as though it consisted of but one row of hairs (Fig. 9). The longest hairs are the third, fourth, fifth, and sixth, at each end they diminish in size so that they together form a very beautiful fan-like structure. The feathering is more or less in one plane, and the hairs end in long, sweeping, very pointed free ends. At the anterior end of the apparatus medially is a single small hair. 
When the larva is at rest hanging on to the surface-film this ventral fan hangs down into the water and presents a graceful appearance, but when the larva seeks the bottom of the vessel and comes to lie on its ventral surface the fan is rather in the way and is bent to one side. This elaborate apparatus may serve as an accessory organ of locomotion, though its delicate structure certainly suggests some sensory (tactile?) function.

The base of the apparatus is further supported by two fine bars of chitin which run forward in the skin. In fact, all the hairs all over the body except on the head, which is uniformly chitinized, are supported by a small, oval plate of chitin with which they articulate. These plates are let into the skin, in fact are parts of the skin chitinized.

The description of the hairs given above applies, roughly speaking, to all the larval stages, it is mainly taken from a medium sized larva. In quite young forms the hairs are smaller and a few may be absent. At any time during the larval existence the hairs may be injured or even broken off. In the older larvae this seems to be especially the case.

\section{Respiratory Openings.}

On the eighth abdominal segment are situated the external openings of the respiratory system supported by a somewhat complex skeleton. In Culex, as is well-known, the larva in this region of the body gives off a long respiratory tube directed dorsalwards. This is much larger and longer than the last segment of the body, and its presence gives the larva the appearance of a $\mathrm{Y}$ with unequal limbs. In Anopheles there is no such tube but the two large tracheae open to the surface by two stigmata which are surrounded and supported by a complex apparatus.

The easiest way to understand the apparatus (Figs. 3, 4 and 15) is perhaps to compare the larva's body to a round stick of soft wood; at one end of this, corresponding with the eighth abdominal segment, we must imagine that a chip has been cut, but remains still attached to the stick though standing out from it. The posterior surface of the chip or the lobe which represents it in the Anopheles is held off from the body by a chitinous ring which forms some two-thirds of a circle; at the sides where this ring is most prominent it forms a curved flattened plate with prominent teeth projecting a little outwards and backwards (Fig. 15). Of these teeth there are some seven large, stout and dark, whilst between and within their bases is a row of smaller less chitinized teeth. These all overhang and guard the space between the chip or 
the lobe and the body, and hold up and keep the lobe standing out from the surface of the body. The two toothed lateral arches are joined together by a thin chitinous bar which runs through the lobe and is continued along the base of the arches to their ventral end, where it splits into a small fork. The recess which is overhung by the lobe and protected laterally by these toothed plates is not the respiratory depression. That is on the dorsal anterior surface of the lobe. Here in the middle is a small squarish space bounded laterally by two thin incurved more or less chitinous plates which are rolled in towards one another like a piece of paper bent into half a cylinder. In front of these and between them and the fan-shaped piece, to be mentioned in a moment, are two minute triangular flaps. The anterior boundary of the square area is formed by an outstanding chitinous plate, fanshaped and stalked, and the stalk runs downward to the middle line of a curiously chequered plate which forms the floor of the area (Fig. 15). Posteriorly the lateral curved-in plates bend in towards one another and unite in a median posterior plate.

The stigmata lie in the anterior lateral corners of this area, closely tucked into the corner and overshadowed by the median anterior fanshaped plate. They are circular in outline with a well-marked thick rim. When breathing the animal lies hanging on to the surface-film by means of its five pair of palmate hairs described above, the edges of the respiratory organ pierce the film and the air is in contact with the squarish area and can enter and leave the trachea. When spread out, the side pieces are more or less unrolled, the triangular flaps are laid back, and the fan-shaped flap bends forward so that its free edge lies anteriorly. The stigmata are most fully exposed to the air. If anything tends to frighten the larva the side pieces and the triangular flaps are curved inwards, the fan-shaped piece folds suddenly back, the connection with the surface-film is broken and the animal darts suddenly below, and frequently carries with it a drop of air attached to the rim of the respiratory recess. Very often the larvae cease lying parallel to the surface, remaining attached only by the edges of this recess, and the anterior end of the body hangs down into the water. At times we have noticed the larva twist itself into a loop and begin cleaning and clearing this complex respiratory apparatus with its mouth organs. We have also seen it carefully clean the posterior bristles which sometimes are covered with débris.

When breathing freely the fan-shaped plate is bent forward so that its posterior face looks upwards, but often it is bent backwards with its 
posterior face downwards. In the former position one can look straight into the stigmata, but in the later the stigmata are partially or wholly covered in. When the larvae leave the surface-film they sink by their own weight, but more generally hasten their retreat by actively swimming downward. This they do by rapidly bending the body first one side and then the other, forming a series of SS, very eel-like. Similarly when leaving the bottom to resume their position beneath the surface-film they swim upwards rather obliquely, until the tail touches the film, when they are suddenly arrested and stop. Very often they shift their position upon the surface by a single sharp side stroke of the tail. They invariably move tail forwards, and the hairs of that part of the body undoubtedly act as buffers. When on the surface they are usually feeding but by no means always, when at the bottom they as a rule lie motionless as if feigning dead. In a glass beaker they are apt to lie with their tails attached to the small concave film which capillary attraction draws up the inside of the glass. In this case the bodies lie radially, the heads pointing towards the centre of the beaker. If kept below the surface, say by a watch-glass, they frequently breathe by attaching the respiratory apparatus to an air-bubble.

At the anterior end of each of the post-thoracic segments on the median dorsal line is a small brown chitinous tergum, this is inconspicuous in the younger stages, and even in the largest larvae it is small. The plates are elongated in a transverse direction, they overlie the heart and are just about as broad as that organ. In the larger larvae they are perhaps about one-fourth or one-third the total width of the segment which bears them, at its narrowest point, which is in fact at the anterior end of the segment just where these terga lie (Fig. 4). They and the other chitinous thickenings, such as the bases of the hairs, are best seen in the cast, larval skins.

After leaving the surface when frightened or otherwise the larvae remain usually below for $\frac{1}{2}$ to 3 minutes, but we have seen them remain as long as 14 and 25 minutes in this situation, alternately feeding and resting at the bottom of the aquarium.

\section{Colour of the Larva.}

The general colour of the younger larvae as seen by the naked eye is black, seen with a lens the head appears of a symmetrically mottled brown, darker where the chitin is thick, lighter where it is thin or 
newly formed. Frequently a light annulation is visible about the prothorax and the tail also is light. From behind the head until about the last two abdominal segments the body appears of a plumbeous black hue. At all times it is the centre of the body that one sees, the sides are so transparent as to be hardly visible, and even when the thorax is much bigger and broader than the head this is often not obvious to the naked eye because the side to whose growth the increased width is due is so transparent.

The older larvae retain their mottled brown colour on their head, but in them the body is lighter than in the young, very often green. This may be due to the food. Down the centre of the back runs a whitish streak, enlarging in each segment, which seems to be caused by some cells along the pericardium. This streak is broken only by the black-brown terga, and each side of these chitinous pieces the white is densest. The green colour is not only in the intestine but at times permeates lightly the tissues in the side of the body, which in the younger larvae are colourless. In the older larvae the five pairs of palmate hairs stand up as black spots on each side of the 3rd, 4th, 5th, 6th and 7th segments, and are well seen in larvae $7 \mathrm{~mm}$. long, in which the thorax $=1.5 \mathrm{~mm}$. broad. After moulting the larvae-at least some of them-are of a lightish lavender colour, very uniform, but they soon darken.

\section{Notes upon the behaviour of Larvae.}

The larvae lie with the long axis of their bodies parallel to the surface of the water. At times, though exceptionally, only the respiratory apparatus is applied to the surface-film, the axis of the body forming a slight angle with the plane of the film. Viewed from the side the respiratory apparatus as also the palmate hairs upon the dorsal surface of the abdominal segments are seen to indent the surfacefilm. The vibratile mouth-parts also disturb the continuity of the surface-film. The palmate hairs just referred to produce a series of minute bilateral indentations in the film, making it appear on superficial observation as if the dorsal surface of the larva actually protruded above the surface. It might be added here that the eggs, as also the respiratory trumpets of the pupae, likewise indent the surface-film. When the wind passes over a pool or ditch containing Anopheles' eggs, larvae and pupae, these will gradually be driven towards the opposite side from which the wind is blowing, though a certain number may 
remain in places sheltered by an overhanging bank. This is due to the impact of the wind against the indented surface of the film.

The head is supported upon a long, thin and muscular neck. The neck is not visible in living larvae, the head seeming to project directly from the thorax. The length of the neck is only fully appreciated in dead larvae, where the parts are relaxed and possibly distended owing to the gases of decomposition accumulating within the body of the larva.

When disturbed the larvae wriggle rapidly tail first to the bottom of the tank, where they lie motionless on the ventral, lateral, or even dorsal surface, the body remaining extended. It is probable that they elude their enemies to some extent by this behaviour. After a few moments, if left undisturbed, they again wriggle tail first to the surface, and soon resume feeding, which in connection with their normally rapid growth is their chief occupation. Whilst feeding, provided they do not change their position through wriggling, the larvae lie stationary beneath the film, only the mouth parts moving. Culex larvae on the other hand, which only adhere to the surface by means of the respiratory apparatus, which when open offers but a small point of attachment to the surface-film, are seen to be continually carried forward through the motion of their mouth-parts alone.

The essential differences between the larvae of Anopheles and those of Culex have been dwelt upon by a number of recent writers. The Culex larva has a very large, broad head, which owing to its weight causes the insect to float head down and almost vertically in the water. It possesses a long respiratory tube containing the two terminally enlarged tracheae, which serve as floats. The respiratory tube ends in five leaf-shaped flaps, which are opened like the fingers of the hand when applied to the surface, and approximated to each other when the insect leaves the surface. Whereas Anopheles is mainly a surface feeder, Culex often feeds at the bottom, browsing about in its normal position, tail uppermost. The larvae of Culex are more readily frightened than those of Anopheles, and return more slowly to the surface than do those of Anopheles, a fact which renders it easy to separate the two genera by the use of a pipette, when found together in a given sample of water. If the larvae of either species cease to move whilst suspended beneath the surface of the water, they are seen to gradually sink to the bottom by virtue of their weight, Culex invariably head-first.

The larvae are not supplied with limbs, locomotion being effected by rapid wriggling motions throughout their length, the direction 
taken being tail-foremost, but otherwise erratic. Possibly the long hairs upon the lateral surfaces, and certainly the long hairs at the terminal segment, act as accessory organs of locomotion, though not of themselves necessarily moveable.

\section{Observations upon the growth of Larvae.}

The following observations were made in tanks in the laboratory, the tanks being cylindrical glass vessels about $2.5 \mathrm{~cm}$. across and containing water about 6 to $8 \mathrm{~cm}$. deep. The tanks were placed near a window where they were exposed to the sunlight during several hours of the day. Fresh Spirogyra and fresh water were added from time to time. It was found unnecessary to renew the water as frequently during cold as during hot weather. The tanks were covered with gauze to exclude dust and prevent any flies from escaping.

Observation 1. Two larvae which had just emerged from the egg measured 0.9 and $0.95 \mathrm{~mm}$. respectively. One was killed and the other measured on successive days. On the second day it was $2 \cdot 4$, the fourth 28 , fifth 4.0 , twelfth $4.3 \mathrm{~mm}$. long. This larva died on the fourteenth day. Average temperature $23-26^{\circ} \mathrm{C}$. (July).

Observation 2. Ten young larvae measuring 0.7 to $0.95 \mathrm{~mm}$. were placed in a tank. Two died on the fourth, two on the sixth, one on the tenth day. They measured on the fourth day 1.5 to $2.0 \mathrm{~mm}$., fifth 1.9 to $2 \cdot 1$, sixth $3 \cdot 0$, seventh $3 \cdot 3$ to $3 \cdot 5$, ninth $4 \cdot 2$ to $4 \cdot 5$, thirteenth $5 \cdot 3$ to 6.4 , fifteenth 6.4 to 7 , eighteenth 7 to $7.5 \mathrm{~mm}$., on which day one pupated, the fly issuing two days later. During the following four days the rest likewise pupated. Temperature during first four days 16 to $19^{\circ} \mathrm{C}$, , afterwards 23 to $26^{\circ} \mathrm{C}$.

The larval stage under the conditions stated lasts from 18 to 21 days. That the larvae attained their full size in the tanks was evident from comparative measurements made upon larvae caught in the open, which soon afterwards pupated. Such larvae measured 6.9 to $7: 3 \mathrm{~mm}$, a quite exceptionally large one measured $8.3 \mathrm{~mm}$. Larvae pupate usually when they have attained a length of about $7 \mathrm{~mm}$., though there is a certain degree of latitude in this respect. The rate of development is greatly influenced by temperature ${ }^{1}$. A few cool days will greatly retard larval growth. It is doubtless due to lowered temperature alone that

1 Howard (1900, p. 39) states, without giving the temperature, that the larval stage of A. maculipennis lasts 16 days. Grassi $(1900, \mathrm{p} .69)$ gives the duration of the larval stage as 20-22 days during the summer in Italy. 
larvae caught in the middle of August had not attained their full growth until November.

Undoubtedly a considerable number of larvae die during the process of development, this no doubt being due in part to difficulties in moulting as also destruction through natural enemies, about which more will be said later. Under natural conditions a very much greater number of small than of large larvae are encountered, and judging from what we see in the laboratory many fully developed larvae die in the attempt to pupate. Of a total number of 834 larvae and pupae caught by one of us at different times in six places in Cambridgeshire, 636 were small larvae (measured up to $4 \mathrm{~mm}$.), and 181 large (measured up to $7 \mathrm{~mm}$.), whereas only 17 pupae were captured. Undoubtedly a number may elude capture, but these figures together with laboratory observation prove that many die off at various stages of growth. The number of pupae caught will naturally be always smaller than that of the larvae because the latter require about eight or ten times as long as the pupae for their developement.

\section{Habitat of Larva.}

The observations cited in the previous paper have shown that the larvae of $A$. maculipennis and $A$. bifurcatus (those of $A$. nigripes have not been found on account of their rarity) are to be found in pools, ditches, backwaters of rivers, canals, and slowly flowing waters in various parts of Great Britain and Ireland. Exceptionally they are found in water that is impure or brackish. Almost invariably the larvae are found in clear water, and usually such as contains algae or Lemna, the latter must however only be present in moderate quantities. The larvae of Anopheles certainly prefer waters that are not shaded by trees. Only once, at Streatley, were they found in a shady spot. This has already been noted by Meinert (p. 478), who writes " elle n'aime pas l'ombre des grands bois, mais recherche le soleil et la lumière, ce qu'indique déjà sa fraîche couleur d'herbe." He found the larvae in Denmark between the end of March and October. It is also exceptional to find them in water contained in small receptacles (troughs, fountain-basins and barrels) such as frequently contain the larvae of Culex. They were found only nine times with Culex larvae, which do not seem to find a sufficient supply of suitable food in the clear water favoured by Anopheles. We find that Grassi (4 Oct. 1899, p. 12) has also observed this in Italy. Anopheles larvae were present only exceptionally with those of Culex 
pipiens and C. annulatus in foul, greenish water at Maccarese, and impure water in fountain-basins near Rome and at Sermoneta. On the other hand he found them frequently in vessels, barrels, disused cisterns, and surface wells at Grosseto, where he thinks that the insects must have been forced to adapt themselves to altered conditions, the old breeding-pools having gradually been removed by drainage from immediate proximity to the town. In America we find Howard (1900, p. 41) reporting the occurrence of the larvae of A. punctipennis (?) in Maryland in a small permanent stream flowing through woods and broadening out into shallows which all contained algae (Mougeotia and Diatoms) which served as food for the larvae. Larvae of $A$. maculipennis were found in pools about a disused spring in Virginia, the water (8-10 inches deep) containing Mougeotia and having a temperature of $18^{\circ} \mathrm{C}$. The larvae of an undetermined species were found in pools in an old canal bed, the water being foul, containing algae (Lyngbya) and showing a temperature of $25^{\circ} \mathrm{C}$. Only empty pupa skins were found in a dried-up surface pool at Washington Barracks at a time when malaria prevailed among the troops. Finally Lazear found A. punctipennis breeding in a stone-quarry near Baltimore. Grassi (1900, p. 58) in Italy found larvae of A.maculipennis along the margins of relatively deep and large pools during the spring, whilst they frequented shallow waters in summer. Ross, Annett and Austen (1900, p. 17) found Anopheles but once in a tub at Sierra Leone, the larvae being absent in fresh-water pools, in mangrove swamps (fish present), as also in shallow puddles liable to desiccation. They were usually present in puddles which continued to hold water, and were not apt to be scoured out by heavy rains. They were also usually present in ditches and pools formed by springs. Whereas $A$. costalis larvae were found everywhere in low parts of Freetown, $A$. funestus was only present in the eastern portion. Stephens and Christophers (July, 1900, p. 45) found the main source of Anopheles during the dry season at Freetown to be pools in the rocky beds of small streams, these pools being situated far out into the bush. At times they also found larvae in spring-fed runnels. During the dry season all rock-puddles remain dry for three months.

In the preceding paper ${ }^{1}$ the occasional occurrence of Anopheles in slightly brackish water is noted. This has also been noted elsewhere, being first mentioned by Grassi (8 June, 1899), who observed it at Metaponto. Christophers and Stephens (Aug. 1900, p. 3) observed Anopheles larvie to occur at Accra in brackish pools $(0.6 \%$ salt), as

\footnotetext{
${ }^{1}$ Studies in Relation to Malaria, Part I.
} 
also in pits about houses. It is interesting to note that they found larvae there in uncovered wells $15-35$ feet deep. It is noted in the preceding Paper $^{1}$ that the larvae of Anopheles were found six times in brackish water in England. In the British Medical Journal (1900, vol. II., p. 400) it has been recently stated that Cook found Anopleeles in 89 tanks in Calcutta. The larvae are found especially where the water is covered by "green scum," but are less numerous where fish abound. Larvae were also found in stagnant ditches containing waste water from the overflow of stand-pipes. Others do not state that the influence of fish is marked. Rogers (Sept. 1900, p. 348) at Maniktolla Principality (Bengal) found larvae to be very common in numerous large tanks swarming with fish, these tanks being the common breeding-places during the dry season when small pools disappear. He also found larvae in small pools containing fish. The larvae of $A$. maculipennis and $A$. bifurcatus were found ten times by Nuttall, Cobbett, and Strangeways-Pigg in collections of water containing fish in England. There can be no doubt but that the larvae obtain a considerable amount of protection from fish through aquatic vegetation, which usually accumulates about the shallow margins of pools. Near Weybridge on the Thames Dr Cobbett (25 Sept., 1900) found larvae along the banks of the river where the ground was marshy and grass grew out of the water. In numerous little pools more or less connected with the river, which appeared to form suitable breeding-places, no larvae could be found. A considerable difference in the temperature of the water in the river and that in the pools was noted, the latter being markedly colder. The weather during the preceding days had been bright and warm during the day, whilst at night it had been cold and sometimes frosty. It is doubtless due to these oscillations of temperature having effect upon the shallow water in the pools that larvae were absent in these. At Byfleet doubtless for the same reason the pools a few yards distant from the river contained no larvae. At Aysgarth in Yorkshire, where no larvae could be found in June and July, larvae were found in September, in grassy pools fed by springs. At this time no larvae could be detected in shallow stagnant pools, containing Spirogyra, not fed by springs and subject to considerable fluctuations of temperature occurring during hot days and cold nights. That there is a difference between A. maculipennis and $A$. bifurcatus with regard to the seasonal occurrence of the larvae is indicated by Grassi (1900, p. 47) and Ficalbi, who found the larvae of the latter species during midwinter in Italy whilst there 
were none of A. maculipennis to be found. We found the first larvae of A. maculipennis in the beginning of May in a ditch; we had not searched for them before this date. On October 20th only two fully developed larvae were found in the Granta after careful search. On the 8th of November Mr Theobald informs us that he found the larvae of this species in all stages of development and in large numbers in a rain-water barrel in his garden. They have been absent all the year round in a couple of pools "where they should be found according to reports," whilst the imago has been nearly always abundant.

It has been claimed by some that the larvae resist desiccation or survive in the mud at the bottom of pools. At first glance this might appear to be supported by two observations we made at Gainsborough and near March, where many fully developed larvae and pupae were encountered in ditches which, according to persons living in the vicinity, had been filled with river water after having been "dry" for 4-7 days. It occurred to us at first that the larvae may have been carried in with the water from the river, as larvae were also found there, but this did not account entirely for the larger number of larvae present in the ditches. The observations of others would indicate that the ditches in question had not been completely dried out. Grassi (17 Sept. 1899) says that he never found larvae nor pupae in moist earth, that is in the absence of water. Christophers and Stephens (1900, p. 20) in Africa found that no large larvae reappeared in a pool which had been dried up for two days and then refilled with rain water. The larvae which did appear issued from eggs which had resisted desiccation for that period. Howard (1900, p. 16) found upon experiment that larvae (presumably of A. maculipennis) only survived 24-48 hours in or upon mud from which water had been drawn off. Under natural conditions he observed culicid larvae to retreat with the receding water of a large pool, and to accumulate in vast numbers in the small amount of water in the deeper excavations at the bottom. In this manner the pool only seemed to be restocked with larvae when it increased in size as the result of rains. 


\title{
74 The Structure and Biology of Anopheles
}

\author{
EXPLANATION OF PLATES.
}

Illustrating the Paper of G. H. F. Nuttall and A. E. Shipley on

"The Structure and Biology of Anopheles maculipennis."

\section{PLATE I.}

Anopheles maculipennis, male $\times$...(See description in a later number of this Journal).

\section{PLATE II.}

Fig. 1. Egg seen from the side $\times 60$. a. the float.

Fig. 2. Egg seen from the upper. surface $\times 60$. a. ridge of air-chambers which acts as a float.

Fig. 3. Very young larval stage $\times 60$. b. brush, $c$. antennae, $d$. palp of 1 st maxilla, $e$. thorax, $f$. stigma.

Fig. 4. Fully grown larva $\times 16$. b. brush, $c$. antenna, d. palp of maxilla, $e$. thorax, $f$. stigma, $g$. palmate hairs, $h$. tergum, $i$. anal papillæ.

Fig. 5. A palmate hair, highly magnified.

Fig. 6. Flabellum or flap which overhangs the base of certain thoracic hairs.

Fig. 7. Side view of head of a fully-grown larva. b. brush, c. antenna, d. palp of maxilla, $m$. hooked hairs at edge of maxilla, $p$. median tuft of hairs, $r$. thickened rim of chitinous covering to head, s. large, feathered hairs which overhang head, $t$. mandible, $u$. larval eye, $v$. eye of adult forming above and behind $u$.

Fig. 8. Ventral view of head of a fully-grown larva. b. brush, c. antenna, $d$. pailp of maxilla, $j$. stout hairs of mandible which arrange the brush, $k$. teeth of mandible, $m$. hooked hairs at edge of maxilla, $p$. median tuft of hairs, $q$. the "under-lip" of Meinert, or metastoma, $r$. thickened rim which passes into the soft tissue of the neck.

Fig. 9. Side view of last segment, showing the four anal papillae and the dorsal and ventral hairs.

Fig. 10. Side view of late pupal stage, $f$. the stigma opening at end of trumpet-like projections.

Fig. 11. Upper or oral view of mandible. $j$. stout hairs which run through the brushes, $k$. teeth, $l$. hairs projecting inwards to mouth.

Fig. 12. Upper or oral surface of first maxilla, d. palp, showing the three spines and the plate. $m$. hooked hairs at edge of maxilla, $n$. hairs lining oral surface of maxilla.

Fig. 13. Dorsal view of the third abdominal segment of a larva about half grown, to show arrangement of hairs, $z$. palmate hair, o. long, balancing hair.

Fig. 14. Ventral view of the same. o. long, balancing hair.

Fig. 15. Stigmatic apparatus seen from above, $f$. stigma, $w$. valve or flap which folds down and breaks the continuity with the surface-film when the animal sinks, $y$. chitinous skeleton which supports the whole apparatus. 


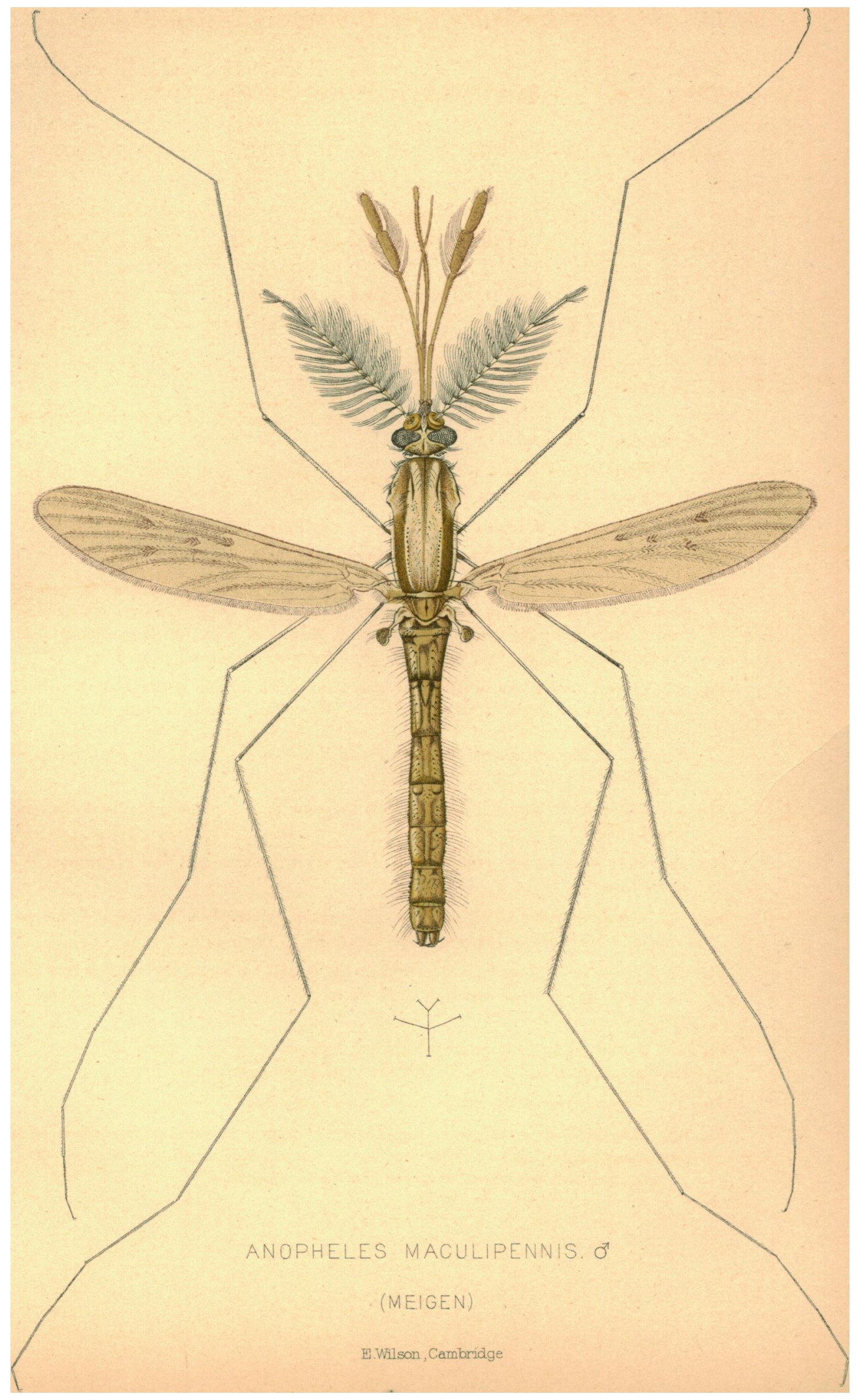




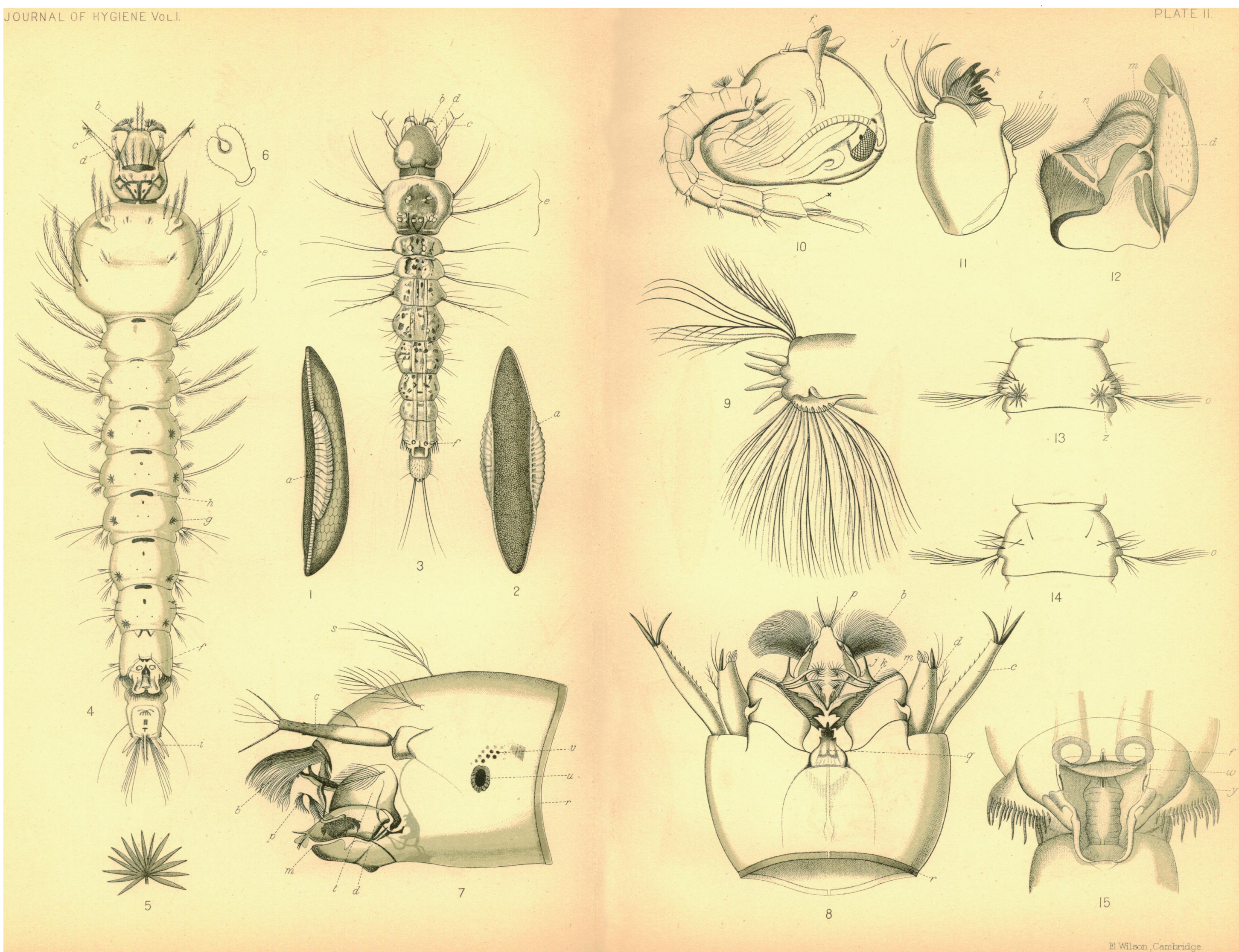




\section{LITERATURE.}

Publications cited both in Parts I. and II. of the "Studies in Relation to Malaria."

Bassett-Smith, P. W. (1900), Observations of Mosquitoes. Journal of Tropical Medicine, vol. III. p. 53. (Oct.)

Brauer, F. (1883), Die Zweiflügler des Kaiserlichen Museums zu Wien. III. Systematische Studien auf Grundlage der Dipteren-Larven etc. Denkschrift d. math.-naturw. Cl. d. Kais. Akad. d. Wiss. vol. 47, pp. 1-96. Plate 1.

Celli, A. and Delpino, G. (1 Sept. 1899), Contributo allo studio dell' epidemiologia della malaria secondo le recenti vedute etiologiche. (Estratto dal Supplemento al Policlinico, Anno 1899, 11 pp. (published in October). Also published in German in Centralbl. f. Bakteriologie, vol. xxvi. pp. 480-486.

Celit, A. and Delpino, G. (1900), Beitrag zur Erkenntnis der Malariaepidemiologie vom neuesten ätiologiscben Standpunkte aus. (Zweite vorläufige Mitteilung.) Centralbl. f. Bakteriologie, Bd. xx viI. pp. 309-313. (10 March.)

Christophers, S. R. and Stephens, J. W. W. (1900), Further Reports to the Malaria Committee, 1900. Royal Society, 22 pp. London (Harrison and Sons, 15 Aug.)

Editorial (1900), Mosquitoes and Malaria in Calcutta. Indian Med. Gazette (Calcutta), vol. xxxv. pp. 400-401. (Oct.)

FiCALBI, E. (1899), Venti specie di Zanzare (Culicidae) Italiane classate e descritte e indicate secondo la loro distribuzione corologica. Bullet. d. Soc. Entomol. Italiana, Anno xxxI. pp. 46-232. 89 figures. Florence.

Fielding-Ould, R. (1900), Observations at Freetown, Accra, and Lagos. Liverpool School of Tropical Medicine, Memoir II. pp. 51-58.

Fischer, G. (1812-1813), Observations sur quelques diptères de la Russie. Notice sur la larve de Culex claviger de Fabricius. Mém. Soc. imp. Nat. Moscou, Iv. pp. 167-180. Plate I.

Giles, G. M. (1900), Description of two species of Anopheles from West Africa. Liverpool School of Tropical Medicine, Memoir II. p. 49-51. (Describes $A$. costalis and $A$. funestus nov. spec.)

Giles, G. M. (1900), A Handbook of the Gnats or Mosquitoes. London (John Baile, Sons, and Danielsson, Ltd.).

Grassi, B. (18 June, 1899), Ancora sulla malaria. R. Accad. dei Lincei, Ser. 5, vol. viII. 1 sem. fass. 12. Seduta del 18 giugno. Reprint 3 pp. (Published 22 June.)

Grassi, B. (31 August, 1899), Le recenti scoperte sulla malaria esposte in forma popolare. Milano. (Estratto dal fasc. 7 (Luglio) della Rivista di Scienze biologiche.) Reprint $55 \mathrm{pp}$.

Grassi, B. (17 Sept. 1899), Ancora sulla malaria. R. Accad. dei Lincei, Ser. 5, vol. virr. 2 sem. fasc. 6 . Reprint 3 pp.

Grassi, B. (Oct. 1899). Osservazioni sul rapporto della seconda spedizione malarica in Italia presieduta dal prof. Koch, composta oltre che dallo stesso Koch, dal 


\section{$76 \quad$ The Structure and Biology of Anopheles}

prof. Frosch, dal dott. Ollwig e coadiuvata dal prof. Gosio, direttore dei laboratori di sanità del Regno d'Italia. Rendiconti d. R. Accad. d. Lincei, Cl. di sc. fis., mat. e nat. Reprint $18 \mathrm{pp}$.

Grassi, B. (1900), Studi di uno zoologo sulla malaria. (9 fig. e 5 tav.) Reale Accademia dei Lincei. Anno ccxcvi. Ser. 5, Memoria della Classe di sc. fis., mat. e nat. vol. III. 209 pp. $4^{\circ}$. (Published 4 June.)

Grassi, B. (1900), Studi ulteriori sulla malaria. Rendiconti d. Reale Accad. dei Lincei. Cl. di sc. fis., mat. e nat. vol. Ix. fasc. 7, pp. 215-224. (Communication of 7 Oct.)

GRassi, B. and Nok, G. (1900), The Propagation of the Filariae of the Blood exclusively by means of the puncture of peculiar Mosquitoes. Preliminary Note. Brit. Med. Journ. vol. II. pp. 1306-1307. (Nov. 3.) Also in Rendiconti d. R. Accad. $d$. Lincei, Ix. 2 sem. ser. 5 a. fasc. 5.

Gray, St George (1900), Anopheles in St Lucia. Brit. Med. Journ. vol. II. pp. 583-584. (Sept. 1.)

Gray, St George (1900), What becomes of the mosquitoes during the dry season? Journal of Tropical Medicine, vol. II. p. 250. (May.)

Howard, L. O. (1900), Notes on the mosquitoes of the United States : giving some account of their structure and biology, with remarks.on remedies. U. S. Dept. of Agricult. Division of Entomology, Bulletin No. 25, n.s. 70 pp. 22 figures. Washington, Government Printing Office. (Recd. Sept.)

JAMES, S. P. (1900), On the Metamorphosis of the Filaria sanguinis hominis in Mosquitoes, especially with reference to its metamorphosis in the Anopheles Rossii and other Mosquitoes of the Anopheles Genus. Brit. Med. Journ. vol. II. (Sept. 1) pp. 533-537), 7 figures. Also Indian Med. Gazette, vol. xxxv. p. 169171 (May), 340-343 (Sept.)

JовLот (1754), Observations d'histoire naturelle, faites avec le microscope, etc. vol. I. part II. chap. L. : "Description d'un nouveau Poisson que j'ai trouvé dans l'eau du bassin de S. Magloire du Fauxbourg S. Jaques à Paris, qu'on peut nommer Chenille aquatique." Pp. 121-123. Plate 14.

Low, G. C. (1900), Filaria nocturna in Culex: probable Mode of Infection of Man. Journ. of Tropical Med. vol. II. pp. 312-313. With coloured plate. (July.) Also in Brit. Med. Journ.

LüHE, M. (1900), Ergebnisse der neueren Sporozoenforschung. Zusammenfassende Darstellung mit besonderer Berücksichtigung der Malariaparasiten und ihrer nächsten Verwanḋten. Centralbl. f. Bakteriologie, Bd. xxvII. pp. 436-460, 9 figures and bibliography, Bd. xxviII. pp. 205-209, 258-264, 384-392.

Macdonald, Ian (16 Sept. 1899), Mosquitoes in relation to malaria. Brit. Med. Journ. vol. II. p. 699.

Manson, P. (1900), Experimental Proof of the Mosquito-Malaria Theory. Brit. Med. Journ. vol. II. pp. 949-951, 2 figures and 1 chart. (Sept. 29.) Also Lancet, vol. II. p. 923-925. (Sept. 29.)

Meinert, Fr. (1886), De encephale Myggelarver. Sur les larves encéphales des Diptères; leurs mœurs et leurs métamorphoses. K. Danske Videnskabernes Selskabs Skrifter, III. pp. 373-493. Plates I-IV. Copenhagen.

Miall, L. C. (1895), The Natural History of Aquatic Insects. London (Macmillan and $\mathrm{Co}_{\text {.). }}$ 
Nuttall, G. H. F. (1899-1900), I. On the Rôle of Insects, Arachnids and Myriapods, as Carriers in the Spread of Bacterial and Parasitic Diseases of Man and Animals. A critical and historical Study. Johns Hopkins Hospital Reports, vol. virr. 154 pp. 3 plates.

II. Die Mosquito-Malaria-Theorie. Centralbl. f. Bakteriologie, vol. xxv. pp. 162-170, 209-216, 245-247, 285-296, 337-346.

III. Neuere Forschungen über die Rolle des Mosquitos bei der Verbreitung der Malaria. Zusammenfassendes Referat. Ibid. vol. xxvi. pp. 140-147, and vol. xxvir. pp. 193--196, 218-225, 260-264, 328-340. (Exhaustive bibliography.) The part on Malaria has appeared in part in the Journ. of Tropical Med. London.

Nuttali, G. H. F. (1900), Article "Filariasis," Encyclopedia Medica, vol. III. pp. 25, with 2 plates and bibliography.

Rees, D. C. (1900), Experimental Proof of the Malaria-Mosquito Theory. Brit. Med. Journ. vol. II. p. 1054. (Oct. 6.)

Rogers, L. (1900), Abstract of a Paper on the Relationship of Drinking Water ;Water-Logging and the Distribution of Anopheles Mosquitoes, respectively to the Prevalence of Malaria North of Calcutta. (From Proc. of the Asiatic Soc., read July.) Inclian Med. Gazette, vol. xxxv. pp. 345-349. (Sept.)

Ross, R. (1900). The Relationship of Malaria and the Mosquito. Lancet, vol. II. pp. 48-50. (July 7.) (Criticisms of a letter by Dauber in the Lancet for June 23, p. 1834.)

Ross, R., Annetr, H. E., and Austen, E. E. (1900). Report of the Malaria Expedition of the Liverpool School of Tropical Medicine and Medical Parasitology. (With Illustrations, Plates and Maps.) Liverpool School of Tropical Medicine, Memoir II. 47 pp. $4^{\circ}$.

Sambon, L. W. and Low, G. C. (1900), On the resting position of Anopheles. Brit. Med. Journ. vol. II. p. 1158 . (20 Oct.)

van der Scheer, A. and Berdenis van Berlekom, J. J. (1900), Malaria en Muskieten in Zeeland. (1 plate) Ned. Tijdschrift voor Geneeskunde, vol. II. No. 14, Reprint 16 pp. (recd. Oct.)

Stephens, J. W. W. and Christophers, S. R. (1900), Reports to the Malaria Committee, 1899-1900. (Royal Society) pp. 42-75. (London, Harrison and Sons, 6 July.)

Theobald, F. V. (1900), A new Anopheles (A. paludis) from Sierra Leone. Reports to the Malaria Committee, 1899--1900 (Royal Society), pp. 75-76. (London, Harrison and Sons, 6 July.)

Ziemann, H. (1900), Ueber die Beziehungen der Mosquitos zu den Malariaparasiten in Kamerun. Deutsche med. Wochenschr. Jahrg. xxvi. No. 25, p. 399. (21 June.) 